\title{
APRENDENDO COM OS MICRORGANISMOS: UMA PROPOSTA PRÁTICA
}

\author{
LEARNING FROM MICROORGANISMS: A PROPOSED PRACTICE \\ Viviane Louback Gitti ${ }^{1}$, Michele Pereira de Souza ${ }^{2}$, Aline Peçanha Muzi Dias ${ }^{3}$, Fátima \\ Kzam Damaceno de Lacerda ${ }^{4}$
}

\author{
${ }^{1}$ IBRAG/UERJ, vivigitti@ig.com.br \\ ${ }^{2}$ IBRAG/UERJ, michelepereiradesouza@yahoo.com.br \\ ${ }^{3}$ FCB/UFF - Campus Universitário de Nova Friburgo, apmuzid@yahoo.com.br \\ ${ }^{4}$ DTPB/IQ/SR-1/UERJ, fatima_kzam@yahoo.com.br
}

\begin{abstract}
RESUMO
Na educação em ciências, a integração entre teoria e a prática é imprescindível para uma melhor compreensão/construção/assimilação dos conhecimentos, se constituindo como um facilitador da aprendizagem. $\mathrm{O}$ mesmo se aplica à microbiologia, área responsável pelo estudo dos microrganismos, onde esta integração possibilita aos discentes compreenderem a importância desses seres para a manutenção da saúde e sua aplicabilidade nas áreas farmacêutica, alimentícia, agrícola, dentre outras. Neste contexto, uma proposta de atividade com materiais alternativos é apresentada de forma que os docentes possam aplicá-la em suas aulas sem a necessidade do uso de um laboratório de ciências, visto que muitas escolas não possuem recursos para a manutenção do mesmo. Os resultados apontam para a possibilidade de trabalhar a microbiologia com estudantes do ensino básico e também com a comunidade em uma perspectiva de pesquisa.
\end{abstract}

Palavras-chave: Microbiologia, Educação, Saúde, Material alternativo.

\begin{abstract}
In science education, the integration of theory and practice is essential for a better understanding / construction / assimilation of knowledge, constituting as a facilitator of learning. The same applies to microbiology, area responsible for the study of microorganisms, where this integration enables students to understand the importance of these beings for the maintenance of health and its applicability in the pharmaceutical, food, agriculture, among others. In this context, a proposed activity with alternative materials is presented so that teachers can apply it in their classes without the need of using a science laboratory, as many schools do not have resources for maintenance. The results point to the possibility of working with microbiology elementary students and also with the community in a research perspective.
\end{abstract}

Key words: Microbiology, Education, Health, Alternative material.

\section{INTRODUÇÃO}

A integração entre a teoria e a prática na educação em ciências possui grande importância no aprendizado. Moraes et al (2008) abordam o tema enfatizando que, no ensino de ciências, as atividades experimentais não devem ser desvinculadas das aulas 


\section{Ensino, Saúde e Ambiente - V 7 (1), Edição Especial, maio de 2014}

teóricas. Segundo os autores, a aula experimental sem integração com a teoria não passa de ativismo, ou seja, atividade corriqueira que se sobrepõem à teoria.

A experimentação é, portanto, essencial para um bom ensino de ciências. Em parte isso se deve ao fato de que o uso de atividades práticas permite maior interação entre o professor e os alunos, proporcionando, em muitas ocasiões, a oportunidade de um planejamento conjunto e o uso de estratégias de ensino que podem levar a melhor compreensão dos processos das ciências (MORAES et al, 2008).

A microbiologia é uma das áreas das ciências que merece muita atenção no quesito aula prática, para que os discentes possam compreender, construir e assimilar quem são e como vivem os microrganismos.

Assim, buscando discutir a importância das atividades práticas sobre o tema acima citado, é apresentada a elaboração de um meio de cultura alternativo que pode ser feito e utilizado pelos professores em aulas práticas lúdicas e dinâmicas. São também descritas as experiências obtidas, por bolsistas de iniciação a docência (ID), em turmas de $1^{\circ}$ e $5^{\circ}$ anos do Ensino Fundamental e $3^{\circ}$ ano do Curso de Formação de Professores, além de uma atividade realizada com a comunidade na Semana Nacional de Ciência e Tecnologia.

\section{COMO ENSINAR MICROBIOLOGIA EM SALA DE AULA?}

A microbiologia é a área da Biologia que estuda os seres microscópicos, denominados microrganismos, incluindo sua relação com o ambiente e com os demais seres vivos. Neste grupo podem ser incluídos bactérias, fungos, algas, protozoários e vírus. Os microrganismos estão em toda parte, são componentes da microbiota humana, auxiliam na agricultura, nas indústrias, nos laboratórios, na produção de alimentos, atuam na reciclagem da matéria e podem, algumas vezes, causar doenças. Alguns exemplos da ação dos microrganismos são: a produção de antibióticos como a penicilina, produto dos fungos Penicillium; a acetona produzida pela bactéria Clostridium acetobutylicum; a febre tifoide, uma doença causada pela bactéria patogênica Salmonella tiphi; a bactéria Agrobacterium tumefasciens que penetra nas células vegetais podendo ser vetor de genes de uma planta para outra. (LIBERTO et al, 2011).

A microbiologia surgiu graças aos experimentos do químico Francês Louis Pasteur que, para demonstrar a existência dos microrganismos, colocou um caldo 


\section{Ensino, Saúde e Ambiente - V 7 (1), Edição Especial, maio de 2014}

nutritivo dentro de um balão, submeteu a fervura e o expôs ao ambiente no centro de Paris e em diferentes regiões dos Alpes franceses, a alturas diversificadas. Pasteur percebeu que no centro de Paris o caldo se mostrava contaminado, diferente das amostras expostas nos Alpes, gerando a ideia de que o ar das montanhas era mais limpo. Mais tarde, o químico demonstrou que se o gargalo dos balões tivesse a forma de pescoço de ganso, o caldo continuaria estéril, ou seja, não sofreria ação de microrganismos que ficariam retidos nas curvas do gargalo do balão, mesmo havendo a introdução de ar. Com esse experimento, Pasteur refutou a hipótese do surgimento dos seres vivos por geração espontânea (LIBERTO et al, 2011).

Louis Pasteur solucionou muitos problemas relacionados à saúde pública, indústria, pecuária, medicina. Ele criou o método da pasteurização utilizado na produção de leite, cerveja e vinho, amplamente utilizado até hoje pelas indústrias, além de ter sido responsável pelo desenvolvimento de inúmeras vacinas, como a anti-rábica, por exemplo. A contribuição deste químico foi de grande valia para a humanidade. (LIBERTO et al, 2011).

Como afirma Cassanti et al (2008), na maioria das vezes os microrganismos surgem no currículo escolar como agentes causadores de doenças, sendo que apenas $2 \%$ das bactérias são patogênicas para o homem. Além deste assunto, acredita-se que outros não menos importantes também deveriam ser considerados ao trabalhar este tema com os discentes como, por exemplo, o uso indiscriminado de antibióticos que resulta no aumento de linhagens resistentes a estas drogas.

Acreditamos, como Cassanti et al (2008, p. 2), que:

O conhecimento básico sobre microbiologia é muito importante para nos tornarmos indivíduos mais conscientes em nosso dia-a-dia, principalmente porque essa área está diretamente relacionada à nossa higiene pessoal e saúde, bem como a inúmeros outros aspectos relacionados ao funcionamento do meio ambiente. Desta forma, o tema merece especial destaque no Ensino Básico.

\subsection{MÉTODOS ALTERNATIVOS}

Como bem apontam Silva e Bastos (2012), muitas escolas públicas não possuem um laboratório de ciências para ministrar as aulas práticas, ficando os conceitos de microbiologia restritos às aulas expositivas. No entanto, as aulas práticas possuem grande importância no ensino de ciências, pois há maior e melhor compreensão do conteúdo abordado (BARBOSA e BARBOSA, 2010), tornando possível que o estudante tenha uma participação efetiva na construção de seu próprio conhecimento. 


\section{Ensino, Saúde e Ambiente - V 7 (1), Edição Especial, maio de 2014}

Desta forma, na ausência de um laboratório e equipamentos, o ideal é que o docente utilize sua criatividade e trabalhe com métodos alternativos, ou seja, substitua os instrumentos de laboratório por materiais que façam parte do seu cotidiano e de seus alunos. Barbosa e Barbosa (2010) descrevem como proceder a esterilização dos materiais a serem utilizados em aulas práticas e construir uma estufa quando não se tem um laboratório de ciências na escola:

- Esterilização por calor úmido - a esterilização possui o objetivo de remover os microrganismos de determinado ambiente. Uma forma muito eficaz de esterilização é por calor úmido feito em um aparelho denominado autoclave. Na ausência deste, pode ser utilizada uma panela de pressão como substituta. Porém, esta deve ficar mais tempo esterilizando já que não é possível atingir a temperatura e nem a pressão da autoclave. (BARBOSA e BARBOSA, 2010).

- Estufa alternativa- A estufa mantém uma determinada temperatura favorável para o crescimento de microrganismos. Na estufa alternativa utiliza-se uma caixa de papelão para abrigar uma lâmpada de forma a converter a energia elétrica (lâmpada acessa) em energia térmica (calor). (BARBOSA e BARBOSA, 2010).

Os meios de cultura são compostos por nutrientes favoráveis à multiplicação dos micróbios, já que são fontes de carbono, fósforo, nitrogênio e açúcares. São vendidos por indústrias especializadas em materiais para laboratórios, mas também podem ser preparados de maneira alternativa com matérias simples (BARBOSA e BARBOSA, 2010).

\subsubsection{PREPARANDO O MEIO DE CULTURA}

Neste trabalho, é proposto o preparo de um meio de cultura com a utilização de materiais do dia a dia, como a panela de pressão substituindo a autoclave, frascos de vidro e plástico como placas de petri e uma estufa caseira feita de caixa de sapato e lâmpada. O objetivo é proporcionar uma maneira de se trabalhar a microbiologia em sala de aula de modo prático, dinâmico e criativo, e sempre associado à compreensão dos conhecimentos teóricos. 


\section{Ensino, Saúde e Ambiente - V 7 (1), Edição Especial, maio de 2014}

De modo a substituir as placas de petri foram utilizados frascos de vidro e plástico como de geleia, papinha de bebê e outros. Os mesmos devem ser cobertos na parte da tampa por papel alumínio, papel pardo e amarrado com barbante, como apresentado na Figura 1.

Figura 1: Frasco de vidro preparado para ser esterilizado.

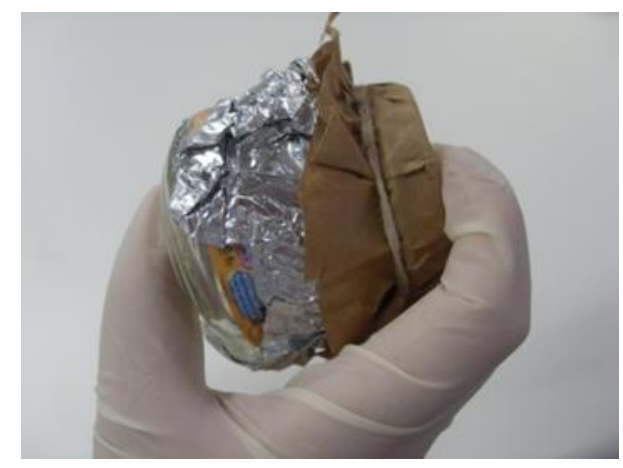

Fonte: Foto de Michele Pereira de Souza

O preparo do meio de cultura é feito utilizando os mesmos reagentes empregados nos meios comerciais para laboratórios, só que comprados de maneira corriqueira em supermercados ou loja de produtos naturais.

Ingredientes do meio de cultura:

- Água 200 mL (aproximadamente um copo de requeijão);

- Leite Desnatado 0,5g (uma colher de chá rasa);

- Glicose (dextrose) 0,2 g (1 pitada de dois dedos);

- Ágar 3 g (duas colheres de chá cheias).

Obs: O ágar ou ágar-ágar é uma substância existente em certas algas e que forma, com facilidade, um gel. É facilmente encontrado em lojas de produtos naturais. O ágar pode ficar mais concentrado na mistura, mas nunca menos concentrado.

O ágar é dissolvido, a parte, em um pouco de água (já contando os $200 \mathrm{~mL}$ ). Misturam-se os outros ingredientes na água e por último o ágar é adicionado na solução formada e novamente são todos misturados. A solução deve ser colocada em um Erlenmeyer (ou uma garrafa de vidro) tampado com algodão, papel alumínio, papel pardo por cima e amarrado com barbante. Depois disso todo o material é colocado em 


\section{Ensino, Saúde e Ambiente - V 7 (1), Edição Especial, maio de 2014}

uma panela de pressão com água até $1 / 4$ da panela, com o auxílio de um apoio para que não fique mergulhado na água. A panela é fechada, levada ao fogo e quando começar a liberar a pressão devem ser contados 20 minutos para desligá-lo. O material é retirado então da panela de pressão.

O meio de cultura assim preparado deve ser despejado, nos frascos esterilizados na panela de pressão, próximo ao fogo, evitando deste modo a contaminação externa (Figura 2). Deve ser despejado o suficiente para cobrir o fundo dos frascos e depois disto colocá-los na geladeira até que o meio de cultura obtenha consistência de gelatina.

A temperatura é um fator que interfere muito na multiplicação das colônias de bactérias. Caso a temperatura ambiente esteja muito abaixo da temperatura ideal para ser trabalhada, é necessário a utilização de uma estufa. Na ausência da mesma é possível montar uma estufa caseira, utilizando uma caixa de papelão, conforme descrito anteriormente (Figura 3).

Figura 2: Preparação do meio de cultura

Figura 3: Estufa de caixa de sapato

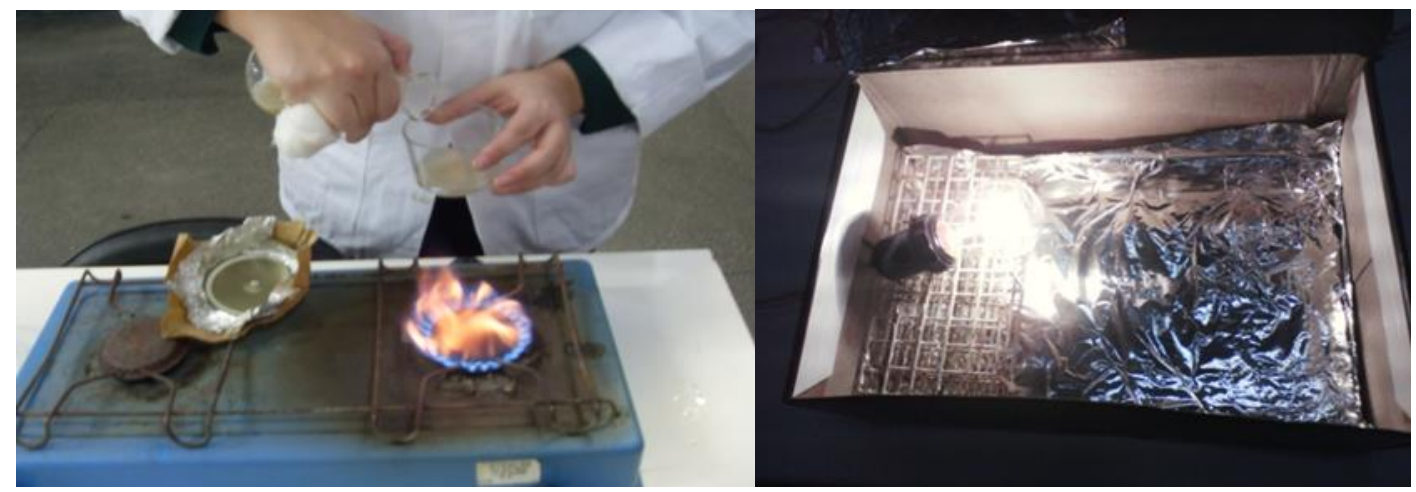

Fonte: Fotos de Michele Pereira de Souza

\subsection{A UTILIZAÇÃO DO MEIO DE CULTURA ALTERNATIVO EM ATIVIDADES EDUCATIVAS: UM RELATO DE EXPERIÊNCIAS}

Existem muitas maneiras de se utilizar o meio de cultura descrito em atividades educativas, podendo o professor abordar temáticas como microrganismos e higiene.

Aqui será feito um relato de experiência, no qual foi utilizado este meio de cultura em atividades em escolas públicas dos municípios de Nova Friburgo e Bom Jardim, no estado do Rio de Janeiro, - a Escola Municipal Maxmilliam Falck (abril de 2012), a Escola Municipal de São Pedro da Serra (novembro de 2012), o Colégio Estadual Ramiro Braga em Bom Jardim (maio/2013) - e em uma feira realizada na Semana 


\section{Ensino, Saúde e Ambiente - V 7 (1), Edição Especial, maio de 2014}

Nacional de Ciência e Tecnologia (Nova Friburgo, outubro de 2013). As atividades foram planejadas e realizadas por bolsistas de ID do curso de Licenciatura em Ciências Biológicas da Universidade do Estado do Rio de Janeiro (UERJ).

Nas duas escolas municipais a temática trabalhada foi a higiene corporal, com turmas de $1^{\circ}$ e $5^{\circ}$ anos do ensino fundamental, alunos com a faixa etária de 6 e 10 anos. Inicialmente foram feitas atividades teóricas com apresentação de slides sobre a importância da higiene para evitar a ocorrência de doenças. Também foram utilizados panfletos, vídeos e ilustrações. Em uma das atividades práticas, os alunos foram instruídos sobre como fazer a higienização correta das mãos, utilizando como estratégia de aprendizagem uma brincadeira com tinta guache: as mãos dos estudantes foram manchadas com a tinta e os mesmos as lavaram com os olhos vendados. Depois, retirando a venda dos olhos e com a ajuda dos colegas, eles percebiam onde haviam deixado de lavar corretamente suas mãos. Os estudantes menores também participaram de uma prática de escovação de dentes utilizando um identificador de placas. No final, os estudantes pintaram figuras relacionadas ao tema estudado e construíram um mural mosaico com o material produzido coletivamente (GITTI et al, 2012).

Para discutir a presença de seres infinitamente pequenos no ambiente que nos rodeia, foram utilizadas duas placas de petri previamente preparadas conforme descrito: uma com o meio de cultura contendo colônias de bactérias provenientes de uma mão contaminada (muitas colônias) e outra placa que apresentava colônias de uma mão higienizada (poucas colônias). As turmas foram convidadas a realizar suas próprias investigações. Para tal, foram divididas em grupos. Cada grupo recebeu uma placa de petri com meio de cultura estéril e escolheu um local da escola para contaminar a mão e inocular os organismos no meio de cultura (refeitório, corredor, sala de aula, banheiro, etc.). O acompanhamento do crescimento das colônias foi feito, ao longo de uma semana, com a professora da turma. Os grupos puderam então discutir sobre os resultados encontrados: quais os locais da escola apresentaram maior "contaminação"; se as colônias obtidas nas placas eram iguais ou diferentes; porque ambientes aparentemente limpos a olho nu, apresentaram colônias ao final de uma semana.

No Colégio Estadual Ramiro Braga, as mesmas atividades práticas foram realizadas com uma turma de alunos do $3^{\circ}$ ano do curso de formação de professores. $\mathrm{O}$ objetivo foi discutir com os futuros professores estratégias para realizar atividades de modo interativo e dinâmico e que envolvesse o cotidiano dos discentes. Os resultados 


\section{Ensino, Saúde e Ambiente - V 7 (1), Edição Especial, maio de 2014}

das experiências vivenciadas com os estudantes do $1^{\circ}$ e $5^{\circ}$ anos do ensino fundamental foram compartilhados com o grupo, bem como as angústias, dúvidas e novas propostas.

A atividade realizada com a comunidade teve como temática "Bactérias.... você sabia?" e aconteceu durante uma feira da Semana Nacional de Ciência e Tecnologia de 2013, numa grande tenda construída na Praça Demerval Barbosa Moreira, em Nova Friburgo/ RJ. Nesta tenda, as instituições de ensino e pesquisa da cidade mostraram seus trabalhos à comunidade. Para esta atividade, foram preparados 60 frascos contendo o meio de cultura alternativo conforme descrito. $\mathrm{Na}$ tenda foi exposto um painel apresentando a contribuição destes microrganismos nas diversas atividades humanas como as indústrias, a saúde e o meio ambiente. Uma placa com um meio de cultura contendo colônias crescidas também foi exposta como forma de chamar a atenção dos visitantes. Os estudantes de diferentes faixas etárias que se mostravam interessados se aproximavam da tenda, aonde era apresentada a temática na forma de diálogo, ou seja, explorando o conhecimento prévio dos mesmos. (Figuras 4 e 5).

Posteriormente os alunos interessados receberam um frasco com o meio de cultura alternativo. Estes escolhiam um local ou parte do corpo para inocular suas bactérias e levavam os meios de cultura para casa ou para a escola, para acompanharem o crescimento das colônias de bactérias. O desafio proposto era mostrar o material ao professor de ciências e aos colegas de turma para que a discussão sobre as bactérias tivesse continuidade através do relato da experimentação de cada estudante.

Figura 4: Material da exposição

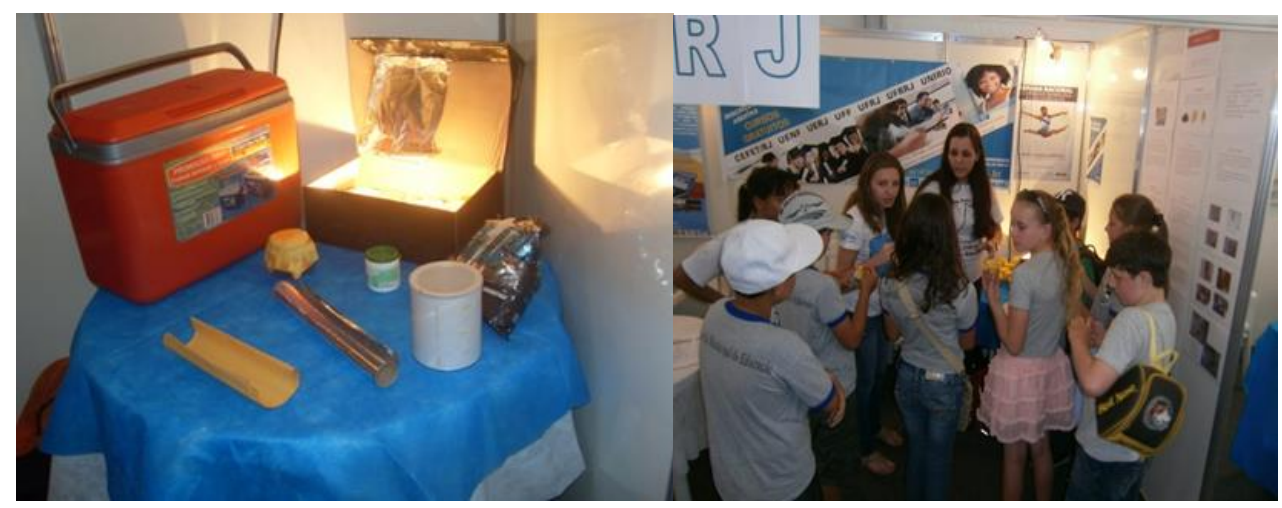

Fonte: Fotos de Viviane Louback Gitti e Michele Pereira de Souza
Figura 5: Diálogo com os visitantes 


\section{Ensino, Saúde e Ambiente - V 7 (1), Edição Especial, maio de 2014}

\section{RESULTADOS}

A metodologia para preparação do meio de cultura aqui descrito foi de fácil execução e apresentou resultados reprodutíveis.

As atividades com os alunos de $1^{\mathrm{a}}$ e $5^{\mathrm{o}}$ anos do ensino fundamental foram muito produtivas, tornando possível que as crianças conhecessem um pouco mais sobre os microrganismos que fazem parte da sua microbiota e de diversos ambientes do espaço escolar, de maneira prática, dinâmica e lúdica. Estes se mostraram muito entusiasmados trabalhando cooperativamente, demonstrando seus conhecimentos prévios em relação ao assunto e descobrindo o mundo dos seres infinitamente pequenos. A interação com os professores das turmas foi fundamental para o desenvolvimento da proposta.

Para os bolsistas de iniciação a docência as experiências foram especialmente relevantes, pois permitiram vivenciar o cotidiano das escolas e compartilhar com os professores de sala de aula o currículo praticado, nos moldes preconizados por Oliveira (2012), ou seja, considerando a indissociabilidade entre teoria/prática, reflexão/ação. Neste contexto, as atividades realizadas com as turmas de formação de professores proporcionou uma importante oportunidade de troca entre grupos com o mesmo objetivo: pensar a própria formação docente.

As atividades realizadas com a comunidade durante a Semana Nacional de Ciência e Tecnologia despertaram um grande interesse, rompendo preconceitos e tabus com relação ao papel dos microrganismos e proporcionando um grande aprendizado, tanto para os expositores/futuros professores como para os visitantes.

\section{CONSIDERAÇÕES FINAIS}

Muito tem sido discutido com relação à educação em ciências em geral e, em especial, ao ensino de microbiologia na educação básica (MORAES et al, 2008; CASSANTI et al, 2008; SILVA e BASTOS, 2012). Faz-se necessário que ações transformadoras sejam tomadas em sala de aula para que não aconteça o que diversos autores têm chamado de "crise no ensino de ciências", que pode se desdobrar em fracasso escolar e desinteresse pelas áreas científicas. (BARBOSA e BARBOSA, 2010, p. 135).

Nesta perspectiva, concordamos que, para um ensino de ciências amplo e qualificado, é de suma importância que se tenha em vista, e como princípio 
fundamental, a pesquisa, que tem como propósito desafiar o professor - a pesquisa como eixo da formação docente - e aproximar e despertar o interesse dos estudantes. (ESTEBAN e ZACCUR, 2002).

Assim, baseados nos resultados obtidos, podemos dizer que o meio de cultura preparado com os materiais e os métodos alternativos aqui propostos, se constitui numa relevante contribuição para transformar essa realidade, fazendo com que os docentes possam realizar aulas práticas com seus estudantes, de todas as idades e de diversos segmentos, mesmo que não exista um laboratório na escola, de forma que estes percebam que os microrganismos estão em toda parte e que possuem grande importância para o planeta e para todos os seres vivos.

\section{REFERÊNCIAS}

BARBOSA, F.H.F.; BARBOSA, L.P.J.L. Alternativas metodológicas em Microbiologia - viabilizando atividades práticas. Revista de Biologia e Ciências da Terra. v. 10, n. 2 , p. $134-143,2010$.

CASSANTI, A.C.; CASSANTI, A.C.; ARAUJO, E.E.; URSI, S. Microbiologia democrática: estratégias de ensino aprendizagem e formação de professores. São Paulo: Enciclopédia Biosfera, 8, p. 1-23, 2008.

ESTEBAN, M.T.; ZACCUR, E. (Org.) Professora-pesquisadora: uma práxis em construção. Rio de Janeiro: DP\&A, 2002.

GITTI, V.L.; ESPÍNDOLA, R.M.; SOUZA, M.P.; FERNANDES, V.S.; LACERDA, F.K.D. Higiene Corporal - Teoria e Prática: Uma Abordagem Integrada. In: VI EREBIO. Rio de Janeiro, 2012.

LIBERTO, M.I.M.; LINS, U.G.C.; CABRAL, M.C. Microbiologia. v. 1, 2 Ed. Rio de Janeiro: Fundação CECIERJ, 2011.

MORAES, R.; ROSITO A.B.; HARRES, J.B.S.; GALIAZZI, M.C.; RAMOS, M.G.; COSTA, R.G.; BORGES, R.M.R. Construtivismo e ensino de ciências: reflexões epistemológicas e metodológicas. 3 Ed. Porto Alegre: EDIPUC, 2008.

OLIVEIRA, I.B. Currículo como criação cotidiana. Petrópolis, RJ: DP\&A, 2012.

SILVA, M.S.; BASTOS, S.N.D. Ensino de Microbiologia: percepção de docentes e discentes nas escolas públicas de Mosqueiro, Belém, Pará. In: III ENECIÊNCIAS, Niterói/RJ, 2012. 